\title{
COMENTARIO A LA POLÍTICA DE ARISTÓTELES
}

Carmenza Neira Fernández

Universidad Santo Tomás

\section{Resumen}

En esta exposición se comparan dos textos-fuente: Comentario a la Política de Aristóteles, de Santo Tomás, y los tres primeros libros de la Política, de Aristóteles. Primero se identifican los textos a comparar, pero como los contextos históricos, políticos y culturales de cada uno de estos dos filósofos son tan distintos, se hace una presentación de los mismos, para ayudar a comprender desde qué experiencias están reflexionando. Desde una perspectiva más filosófica se presentan los puntos de vista y métodos utilizados por los autores en los textos y, en algunos casos, a partir de los ejemplos que utiliza Santo Tomás, se trata de mostrar la diferencia en la comprensión de las categorías del discurso político.

\section{Palabras clave}

Aristóteles, Tomás de Aquino, política, contexto político, contexto cultural.

\section{Abstract}

In this composition, I compare the texts The comment of the Aristotle's Politics of Saint Thomas and the first three books of Aristotle's Politics. First, I identify the texts by comparing, situating them in their context, to be able to understand their differences.

Thus, from a philosophical perspective, these points of view are shown with the examples and methods of each philosopher, comparing their differences and similarities. Finally the examples used by Saint Thomas show us the differences of the conception of the political categories and his contribution, specially in what concerns to the slavery theory. 


\section{Key words}

Aristotle, Aquinas, politics, political context, cultura context.

\section{Introducción}

El Comentario a la Política de Aristóteles ${ }^{1}$ es una de las obras póstumas de Santo Tomás. Sus biógrafos nos cuentan que Santo Tomás, como discípulo de San Alberto Magno, conoció a fondo el Comentario de San Alberto Magno a la Política y se cree que se apoyó en él al redactar el suyo. Pero como no es conocida la edición en imprenta del Comentario de San Alberto, nos tenemos que contentar con basarnos solamente en la obra de Santo Tomás.

La época en que escribió este Comentario corresponde a su última estadía en París, entre 1269 y 1272 . Sólo comentó los libros I y II, y los seis primeros capítulos del libro III.

Parece que su intención, más que dar a conocer un pensamiento político, fue la de entrenar a sus discípulos en la lectura, análisis y comprensión de textos. En ese entonces, tal vez como hoy, era común la queja de que los estudiantes no sabían leer y comprender textos filosóficos. El comentario de texto fue un género literario muy utilizado en ese tiempo por sus calidades pedagógicas.

Para 1269 Santo Tomás ya había escrito las otras obras donde se encuentra su pensamiento político: La Summa Theologica I Pars (1267-1268), la Summa Contra Gentes (1265), y De Regno (1267).

Conviene observar que el Comentario a la Política de Aristóteles no contiene todo el pensamiento político de Santo Tomás, y que su doctrina política, iluminada por la teología, supera y trasciende los principios y análisis de la política griega.

Esta exposición se centra exclusivamente en el texto del Comentario a la Política, sin tener en cuenta las otras obras de Santo Tomás.

Para comenzar, conviene destacar dos características que hacen de este texto una obra excepcional: primera, que como toda verdadera filosofía, la reflexión se hace en diálogo con el pensamiento de otro filósofo, se hace en diálogo con los textos. Es ahí donde se analizan con rigor los pensamientos, los conceptos, los argumentos. El texto de Tomás sigue paso a paso, frase a frase, el texto aristotélico, y se nota el esfuerzo por lograr una comprensión y una traducción al contexto de la época. Por ello este Comentario de Santo Tomás podría considerarse como un antecedente de la exégesis y de la hermenéutica del texto. Segunda, el enfoque ético que parece predominar en el texto de Tomás, incluso en lo que se refiere a lo que hoy podríamos llamar "Tratado de economía”. Aristóteles aporta los elementos, los conceptos, y Santo Tomás con sus comentarios acentúa el juicio negativo respecto a la acumulación del dinero y al desequilibrio de la administración doméstica. Encontramos aquí ya expresadas categorías que luego se conocerán a través de las teorías de Adam Smith y de Karl Marx.

1 Tomás de Aquino y Pedro de Alvernia, Comentario a la Política de Aristóteles, trad. y notas de Ana Mallea (Pamplona: Eunsa, 2001). 
Como podemos ver, abordar el Comentario a la Política de Aristóteles de Santo Tomás es una tarea interesante, pero nada fácil. Presentaremos aquí algunas de las dificultades que hemos encontrado.

Primero, el problema de tener que trabajar con lo que podemos llamar dos fuentes esquivas. Tanto el manuscrito en griego, en papiro, de Aristóteles, como el códice latino de Santo Tomás han llegado a nuestras manos desfigurados por las mediaciones. Por otra parte, parece que ninguno de los dos textos es en su integridad de la autoría de los Maestros.

En el caso de Aristóteles, la Politeia parece ser la colección de las memorias que los discípulos del Liceo escribían después de los diálogos con su maestro y que luego éste corregía y ordenaba. Trabajó en la Política durante diez años y parece que fueron sus discípulos quienes la terminaron tras su muerte. Para esta exposición hemos utilizado la traducción del griego al castellano del padre Manuel Briceño, S.I. ${ }^{2}$

En el caso de Santo Tomás, sólo comentó los tres primeros de los ocho libros que conforman la Política de Aristóteles; murió sin completar el tercer libro, y el trabajo fue terminado por su discípulo Pedro de Alvernia. De la Política de Aristóteles no hay más comentarios en la Edad Media; parece que Alberto Magno hizo uno, pero no se conserva. Para esta exposición nos vamos a limitar al Comentario de Santo Tomás.

Otra dificultad es la de las traducciones. La obra de Aristóteles, escrita en griego común, fue legada en testamento por el Maestro a Teofrasto, un discípulo del Liceo, quien, a su vez, la legó a Neleo. Neleo, por miedo a que el rey de Pérgamo se la llevara como botín de guerra, la escondió en una cueva y allí duró perdida esta obra por ciento ochenta y siete años, hasta que fue encontrada y comprada por un coleccionista, Apelicón de Teos. En la época de Mario y Sila, éste último se llevó como botín para Roma la obra de Aristóteles (86 a.C.) Allí fue organizada por Andrónico de Rodas. Las primeras traducciones de obras de Aristóteles al latín se hicieron en el siglo XIII. Una de ellas, la que fue utilizada por Santo Tomás, fue la de Guillermo de Moerbecke, dominico, compañero del santo. Pero posteriormente esta versión de Moerbecke fue modificada, para realizar la segunda edición en 1942, por Luis de Valencia, quien suprimió todas las referencias al vocabulario en griego y las sustituyó por perífrasis. Por ejemplo, oligarchia es reemplazado por paucorum status, democratia por popularis status y politeia por republica.

Del Comentario a la Política de Aristóteles de Santo Tomás se han hecho ya en imprenta catorce ediciones basadas sólo en tres manuscritos. La edición de 1492 es la base de todas las ediciones posteriores. Se encuentra una edición llamada Leonina ${ }^{3}$ que corrige algunos aspectos de la edición de Luis de Valencia. Para esta exposición nos basamos en la edición de Eunsa ${ }^{4}$.

Finalmente, un inconveniente, y tal vez uno de los mayores, consiste en la diferencia de métodos de análisis y exposición. En Aristóteles, el método es inductivo: observa las diferentes organizaciones y costumbres, y desde estas observaciones hace sus reflexiones. Por ejemplo:

Aristóteles de Estagira, Politeia, trad. de Manuel Briceño, S.I. (Bogotá: Instituto Caro y Cuervo, 1989). Editada bajo el título de Sententia libri politicorum, S.T.A., Opera omnia, Issu Leonis XIII, Romae, 1971. Aquino y Alvernia, Comentario... 
Quien considera las cosas desde el comienzo verá en ellas excelentes conclusiones. En primer lugar, debe haber unión por parejas en los seres que no pueden existir sin los otros, como el macho y la hembra para la perpetuación de la especie, por impulso natural, como en los animales y las plantas; (...) y por naturaleza uno manda y otro obedece para la supervivencia. Quien con la inteligencia es capaz de prever está naturalmente destinado a ser amo y quien tenga fuerza corporal es por naturaleza esclavo. Por eso hay un interés mutuo entre amo y escla$\mathrm{vo}^{5}$.

La comunidad de varias aldeas es la polis, que tiene, por así decirlo, el más alto grado de autarquía: se forma para vivir y existe para vivir bien. Así toda polis es natural, ya que también lo son las sociedades primitivas que les dieron origen ${ }^{6}$.

En Santo Tomás, la reflexión y el análisis no se hacen sobre una realidad social (que él desconocía), sino sobre un texto y su forma de argumentar. Esto enriquece mucho la reflexión de Santo Tomás y nos muestra el esfuerzo inmenso que realizó para comprender un texto que tenía para él referentes desconocidos.

Encontramos que analiza la argumentación, hasta el extremo de convertir en silogismos las afirmaciones de Aristóteles, para mostrar cómo prueba la premisa mayor o la menor:

En todas las comunidades se encuentra que hay una que predomina y otra que está sujeta y esto es natural y conveniente.
El hombre es naturalmente un animal político y es natural que constituya comunidad.

Toda comunidad constituida por hombres tiene una parte que gobierna y otra naturalmente sujeta y esto es beneficioso.

Prueba la primera premisa:

- en lo inanimado (la armonía del cosmos)

- en el hombre (alma-cuerpo)

- en los animales amaestrados (hombreanimal doméstico)

- en la diferencia de los sexos (hombre-mujer) ${ }^{7}$.

Sin embargo, como Santo Tomás está siguiendo casi literalmente el texto aristotélico, las pruebas no pueden ser por el análisis de los conceptos y de la estructura y corrección del silogismo, sino que han de asumirse como pruebas las descripciones del texto aristotélico.

Encontramos también que, en algunas partes del texto, Santo Tomás se ve obligado a aclarar términos que de otro modo llevarían a confusión. Ejemplo:

Dice que entre los bárbaros se tenía a la mujer y al siervo como del mismo orden. (...) Pero puede haber una duda sobre a quiénes debe llamarse bárbaros. Algunos dicen que bárbaro es todo hombre al cual no se le entiende el idioma que habla. De ahí que el apóstol diga: ¿Si yo no entendiera el

Aristóteles, Politeia ..., Libro I, 1, 1252a (p.133).

Aristóteles, Politeia ..., Libro I, 2, 1252b (p. 135).

Aquino y Alvernia, Comentario..., Libro I, Lección III, \# 32,33,34,35,36,37 (p. 41-43). 
significado de la voz seré bárbaro para aquel a quien hablo, y el que habla lo será para mí. (...) En realidad todos se aproximan de alguna manera a la verdad, dado que en el término bárbaro se capta la idea de algo extraño en sí o para alguno. Se considera que es en sí mismo extraño al género humano quien flaquea en la razón por la cual se dice hombre, y por eso se denominan propiamente bárbaros los que tienen una razón deficiente, sea por la inclemencia del clima que les tocó en suerte, sea porque debido a la disposición misma de la región se encuentran muchos hombres enervados o embotados. $\mathrm{O}$ bien por alguna mala costumbre existente en algunas tierras, de la cual proviene que los hombres se vuelvan irracionales y como brutales. (...) Ahora bien, es algo notorio que de la fuerza de la razón procede el que los hombres se rijan por un derecho razonable, que usen la escritura y sepan leer. De allí se desprende que la barbarie se ponga en evidencia por esta pauta: porque esos hombres no emplean leyes o las usan irrazonablemente, y de manera similar que en algunos pueblos no usen la escritura ni sepan leer 8 .

\section{Temas comunes}

Hemos seleccionado para esta exposición algunos temas en los que parecen coincidir Santo Tomás y Aristóteles y que consideramos están aún vigentes como problemas en la actualidad. Son estos: la naturaleza de la polis; la formación de la polis; la teoría de la esclavitud y del derecho a la guerra; y lo que llamamos el "Tratado de economía”.

\section{Naturaleza de la polis}

\subsection{En Aristóteles}

Toda polis es en alguna manera una

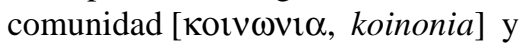
pues vemos que toda comunidad es instituida en vista de un bien, es claro que todas tienden a un bien, pero al principal de todos tiende con mayor razón la más poderosa de todas, que abarca a las demás. Esta es la llamada polis y comunidad política9 ${ }^{9}$.

En una nota a pie de página en la traducción del padre Manuel Briceño, S.I., se aclara que los griegos tienen dos palabras para designar la ciudad: polis (asty), que indica lugar, en sentido material y se opone a polis (polis), que originalmente significaba "fortaleza" (akropolis, acrópolis). Con el tiempo polis viene a indicar, en palabras mías, el cuerpo cívico, la comunidad política organizada como un todo; o el número limitado de ciudadanos suficiente para vivir bien dentro de los límites de un territorio común, con autarquía y autonomía, en obediencia a las leyes.

La politeia (politeia), la política, implica la existencia de magistraturas.

La koinwnia (koinonia), significa comunidad. La comunidad política es una asociación entre iguales y pares.

El político que maneja los asuntos de la polis es un primero entre pares. No es ni un rey, ni el padre de familia, ni el amo de los esclavos ${ }^{10}$.

\footnotetext{
8 Aquino y Alvernia, Comentario..., Libro I, Lección I, \# 9 (p. 41).

9 Aristóteles, Politeia ..., Libro I, 1, 1252a (p. 131-132).

10 Cf. Aristóteles, Politeia ..., p. 132.
} 


\subsection{En Santo Tomás}

En los numerales 1 y 2 de la Lección Primera comenta Tomás este texto de Aristóteles. Hace una síntesis de la forma como Aristóteles plantea el tema:

Sobre el primer punto prueba que la ciudad se ordena a algún bien como a su fin y después prueba que el bien al que se ordena la ciudad es el principal de los bienes humanos.

Con respecto a lo primero, propone este razonamiento:

Toda comunidad es instituida por algún bien

La ciudad es una comunidad

Luego la ciudad es instituida por algún bien.

Como la menor es manifiesta, prueba la mayor ${ }^{11}$.

Aquí sería interesante aclarar qué es lo que Santo Tomás entiende por bien común, lo que designa Aristóteles como "bien vivir" como efecto de la vida organizada en comunidad. Pero este tema será objeto de una exposición especial.

\section{Formación de la polis}

Este es uno de los temas más espinosos en el Comentario de Santo Tomás. El enfoque de Aristóteles combina un principio metafísico, "El todo se compone de partes y el todo es metafísicamente primero que las partes”, y un recuento histórico de cómo se formaron las polis griegas.
Primero el oikos (oikos) o comunidad familiar compuesta por el hombre, la mujer, los hijos y los esclavos, en el que predomina el poder del hombre sobre la mujer, de los padres sobre los hijos y del amo sobre el esclavo; el demos (demos) o pueblo, aldea, asociación de familias; y por último la polis (polis) que congrega bajo las leyes y con autosuficiencia varios demos.

Conviene, en este punto, ampliar la información sobre cómo se formó la cultura griega. Jean Pierre Vernant ${ }^{12}$ describe la formación de los pueblos de la Hélade desde el año 1900 a.C.

Hacia el año 2000 a.C. habitaban en Creta, el mar Egeo y la península balcánica, los pelasgos, habitantes prehistóricos que tenían una cultura de cara al Oriente. En el 1900 llegaron unas hordas indoeuropeas, que venían de las estepas de Rusia, con características propias, que ya hablaban un griego muy arcaico, y se impusieron en Creta y Micenas creando la cultura Cretomicénica. Son estos los antepasados de los troyanos de Homero, los pueblos de los caballos, del hacha de guerra y de la cultura del bronce. A ellos se deben obras de arquitectura como el palacio de Cnossos. Cuando Creta construye Cnossos, su primera civilización palatina (2000-1700 a.C.), queda orientada hacia los reinos del Cercano Oriente. Con la costa siria entran en contacto con Egipto. Es la cultura de los nimios que se prolongó hasta el siglo XIV a.C.

La vida social micénica aparece centrada en torno del palacio, cuya función es religiosa, militar, política y administrativa. El rey ó anax (ánax) concentra en su persona todos los elementos del poder. En esta economía no cabe comercio ni propiedad privada.

Aquino y Alvernia, Comentario..., Lección I, \#1 (p. 36).

12 Jean Pierre Vernant, Orígenes del pensamiento griego (Buenos Aires: Eudeba, 1979). 
Hay dos formas de tenencia de la tierra: primera, frente al Palacio se entrevé un mundo rural organizado en villorrios, demos, con vida propia. Se trata de gente rústica que dispone de una parte de las tierras para actividades pastoriles y agrícolas. En este cuadro aparece el basileos (basileos) homérico. No es el rey en su palacio, sino un señor, vasallo del ánax. Junto al basileos hay un Consejo de Ancianos (ãerousia, gerousia).

En el siglo XII a.C. la invasión dórica destruye este conjunto. Rompe los vínculos de Grecia con Oriente y se regresa a una economía puramente agrícola. Al caer el imperio micénico, cae el sistema palatino. El término ánax desaparece y se asume basileos como rey.

Con la caída del imperio micénico y la expansión de los dorios (antepasados de los espartanos) por el Peloponeso se inaugura otra etapa: la Edad de Hierro. Los aqueos huyen a las costas de Asia Menor y marcan una ruptura decisiva con Oriente. Buscan en sus comunidades, regidas por la sabiduría, la fortaleza social. Se crean los arcontes (de arché, principio de autoridad), y en el siglo VI a.C. se comienzan a escribir las constituciones de sus polis. Se delibera en común y en el ágora. La aparición de la polis (s.VII a.C.) marca un acontecimiento decisivo: el nacimiento de las ciudades-estado. La polis implica el poder de la palabra, del debate, de la argumentación y de la escritura ${ }^{13}$.

Aristóteles plantea su reflexión sobre estas polis concretas y selecciona los elementos que encuentra comunes.

El enfoque de Santo Tomás es el de un típico medieval. No puede hablar de Edad de Bronce, ni de Edad de Hierro; ni tiene como referentes las culturas homéricas (Ítaca, la Argólida, Troya).

El desplome del Imperio Romano y su mezcla con los pueblos "bárbaros" (godos, visigodos, vándalos, lombardos) da como resultado en Italia y en toda la Europa Occidental latina una organización feudal en la que el castillo o el monasterio eran la fortaleza y el soporte de la economía. Con las luchas por el poder entre el Sacro Imperio Romano Germánico y el Papado, sobre todo en Italia, los señores feudales se encontraban en el predicamento de servir a uno u otro señor. La familia de Aquino, descendiente de lombardos, con su castillo de Roccaseca y sus vínculos con el emperador Federico II, nieto de Barbarroja, era más gibelina que güelfa. Al excomulgar Inocencio IV a Federico II, esta familia se muestra más prudente en su adhesión al emperador. Como podemos ver, la experiencia política de la época de Santo Tomás no puede permitir una comprensión de la polis cercana a la griega. Por otra parte, al perderse el peso semántico del vocabulario griego, y traducir como civitas la palabra polis (polis), la concepción se centra en su acepción como lugar que recoge varias aldeas, concepto que en mi criterio es casi inconcebible (a no ser bajo el moderno término de "connurbanización" que designa el modo como las metrópolis modernas anexan pueblecitos vecinos), pero que en el de Tomás se puede asimilar a organización de gremios: los artesanos, los fundidores, etc.

En la Lección I, Santo Tomás interpreta que Aristóteles está comparando la polis con otras comunidades, e interpreta la relación oikos, demos, politeia como elementos que genéticamente han constituido la polis. Examinemos la comparación que hace para mostrar la relación del compuesto y sus partes:

$13 \quad$ Vernant, Orígenes..., pp. 11-27. 
Para conocer una palabra se requiere dividirla hasta llegar a las letras, y para conocer un cuerpo natural mixto hay que dividirlo en sus elementos ${ }^{14}$.

Y así trata sobre la comunidad de la pareja, de la familia, del vecindario y de la ciudad.

La finalidad de Aristóteles es probar que el hombre es animal político por naturaleza, y lo prueba por la operación propia del hombre, de tal manera que su sociabilidad es mejor que la de la abeja y otros animales gregarios. Describe las diversas comunidades para aclarar diferenciando. Tiene como principio metafísico el que el todo tiene prioridad sobre las partes, de manera que la ciudad tiene prioridad sobre las otras comunidades.

A Santo Tomás le llama más la atención el planteamiento del siguiente problema: si es lo mismo la comunidad política que la comunidad familiar y si sólo difieren en cantidad. Distingue un doble régimen, el del amo o déspota, y el del ecónomo o procurador y administrador de la sociedad doméstica. Distingue también cuando un hombre gobierna simplemente y en todo, a lo cual llama régimen real, y cuando gobierna según normas expresas, a lo cual llama régimen político. Distingue la comunidad doméstica (que se ordena para lo cotidiano) de la comunidad política. Al tratar de la ciudad, muestra la condición de ésta en cuanto a tres aspectos:

Primero, señala los componentes de la ciudad, así como el vecindario está constituido por casas, la ciudad lo está por muchos vecindarios ${ }^{15}$.
Parece como si Santo Tomás interpretara la descripción del origen natural de las comunidades humanas como descripción de elementos constitutivos del todo social, asimilando los gremios medievales de artesanos, etc., a los demos griegos, bajo el nombre de “vecindarios". Con esto se pierde un poco la definición filosófica de polis que aporta Aristóteles.

Segundo, es una comunidad perfecta y lo prueba dado que si la comunidad de todos los hombres ha de ordenarse a lo necesario para vivir, la comunidad perfecta será la que se ordene a que el hombre posea con suficiencia lo necesario para vivir ${ }^{16}$.

En el tercer aspecto coincide con Aristóteles en que la polis debe ser autosuficiente, autónoma y regirse por leyes, porque se trata de comunidad de seres racionales.

\section{Teoría de la esclavitud}

\subsection{En Aristóteles ${ }^{17}$}

Es claro que unos hombres son libres por naturaleza y esclavos otros, y por esta razón la esclavitud es conveniente y justa para éstos ${ }^{18}$.

Aristóteles argumenta a partir de la relación alma-cuerpo; inteligencia-apetitos; y el poder del hombre sobre los animales amaestrados.

Es la tesis del poder del amo sobre el esclavo y del gobernante sobre el súbdito.

\footnotetext{
Aquino y Alvernia, Comentario..., I, \#5 (p. 38).

Aquino y Alvernia, Comentario..., Lección I, \#17 (p. 45).

Aquino y Alvernia, Comentario..., Lección I, \#17 (p. 45).

Aristóteles, Politeia..., Libro I, 5, 1255a (p. 142).

18 Aristóteles, Politeia ..., p. 142.
} 
Los más inteligentes mandan (los griegos a los bárbaros); el hombre a la mujer. Los más fuertes de cuerpo y poca inteligencia obedecen.

El esclavo es propiedad del amo, es un artículo vivo de la propiedad.

Aquí pone la metáfora de las lanzaderas:

Si las lanzaderas tejieran solas y los plectores tañeran las cítaras, entonces ni los patronos necesitarían obreros, ni los amos esclavos $^{19}$.

Trata también Aristóteles del esclavo que es botín de guerra, esclavo por ley y no por naturaleza.

Es interesante traer aquí la nota a pie de página del padre Briceño a propósito de este tema:

Aristóteles es el defensor de la esclavitud pero es también el reformador. Combate las tesis brutales en virtud de las cuales todo hombre, pese a las más elevadas cualidades, pudiera ser esclavo. Ordena tratar a los esclavos como a seres racionales. La falla está en la creencia de que el uso de su época corresponde a necesidad de la naturaleza ${ }^{20}$.

\subsection{En Santo Tomás ${ }^{21}$}

Parte del principio de que hay hombres destinados por naturaleza a servir y otros a mandar y que esto es beneficioso. Se distinguen las clases de sujeción y de gobierno, en la pareja, en la comunidad familiar, el amo y el siervo, y en la política el rey y su reino. Aristóteles habla del gobernante y no del rey.

Destaca Santo Tomás un punto interesantísimo: la diferencia entre el hombre-siervo y el animal:

El que es naturalmente siervo participa de la razón sólo en cuanto a recibir el sentido de la misma, como educido por otro, pero no en cuanto a tener el sentido de la razón por sí mismo. Los demás animales sirven al hombre no como recibiendo del hombre algún sentido de la razón, o sea, en cuanto a la memoria de lo bueno o malo que vivieron por parte del hombre los incita a servirlo, por temor o por amor.

Difieren, pues, en cuanto al modo de servir, dado que el que naturalmente es siervo sirve con la razón y el animal lo hace con la vivencia de temor o amor grabada en la memoria de lo bueno o malo que vivió al lado del hombre ${ }^{22}$.

También aclara Santo Tomás: "hablan lo mismo del hombre libre que de la libertad: hombre libre es el nacido libre, ni siervo, ni liberto"23.

Estas tesis sobre la esclavitud son muy importantes para nosotros, en América Latina, porque basándose en interpretaciones de esta parte de la Política de Aristóteles se justificó la conquista de América y el sometimiento de los indios, sobre todo en las tesis de Ginés de Sepúlveda en su polémica con fray Bartolomé de las Casas.

\footnotetext{
Aristóteles, Politeia ..., p. 53.

Aristóteles, Politeia, p. 60.

Aquino y Alvernia, Comentario..., Libro I, lección III, \# 30-42.

Aquino y Alvernia, Comentario..., Libro I, Lección III, \# 39 (p. 60).

Aquino y Alvernia, Comentario..., \#51 (p. 66).
} 


\section{Tratado de economía o "Sobre la administración doméstica y la crematística"}

\subsection{En Aristóteles ${ }^{24}$}

Hemos demostrado que el esclavo es parte de la propiedad. Estudiemos ahora la propiedad en general y la crematística. Primero, preguntémonos si esta última es igual a la administración doméstica, o es parte o instrumento de ella y en último caso si es como la lanzadera al arte textil o la fundición del bronce a la estatuaria. No son instrumentales de igual manera, pues la una provee de instrumento y la otra del material ${ }^{25}$.

Aquí utiliza Aristóteles una analogía de proporción: la lanzadera es al arte textil como la crematística es a la administración doméstica y no como el bronce a la estatuaria. La crematística suministra el material y la administración doméstica lo emplea. De aquí que sean distintas.

Aristóteles analiza cómo las diferentes formas de subsistencia determinan los diferentes modos de vida, y describe las que se conocen en el s. IV a.C. en Grecia: nómadas, pastores, agricultores, cazadores, piratas, pescadores y agricultores. Todos estos ganan el pan con trabajo productivo y no por mercadeo, pero anota que hay también quienes de la combinación de oficios se ganan la vida fácilmente, supliendo con uno las deficiencias del orto, por ejemplo el ladrón. En este contexto justifica el arte de la guerra como un medio natural de subsistencia. Este es un punto importantísimo, porque en él se basa- ron los que justificaron en el siglo XVI las guerras de conquista y colonización.

El arte de la guerra es, en cierto sentido, un modo natural de adquisición (del cual la caza es una parte), que debe practicarse no sólo contra las bestias salvajes sino aun contra aquellos hombres que, destinados por la naturaleza a la sujeción, no lo aceptan, pues una guerra de esta clase es naturalmente justa ${ }^{26}$.

Concluye Aristóteles que estas maneras naturales de adquirir lo necesario para la vida son parte de lo que el denomina "administración doméstica” y que así es como se amasa la "riqueza verdadera".

A continuación opone la manera natural de adquirir para la subsistencia $a$ la forma de enriquecerse por el dinero, a la que llama "crematística”.

Existe una manera natural de adquirir, que es parte de la administración doméstica, en cuanto que lo necesario para la vida esté a nuestra disposición o debe almacenarse para utilidad de la comunidad política o de la familia. De estos elementos a nuestro parecer se amasa la riqueza verdadera. La cantidad de bienes suficiente para una vida próspera no es ilimitada. (...) La riqueza es la suma de instrumentos destinados a la administración doméstica y de la polis ${ }^{27}$.

Aristóteles procede luego a mostrar diversas formas de adquisición: el cambio o trueque, la venta, y hace el análisis del valor de uso y el valor de cambio de un objeto.

Aristóteles, Politeia ..., Libro I, 8, 1256a.

Aristóteles, Politeia ..., Libro I, 8, 1256a (p. 146).

Aristóteles, Politeia ..., Libro I, 8, 1256b (p. 149).

Aristóteles, Politeia ..., Libro I, 9, 1257a (p. 149). 
Pero hay otra variedad de adquirir, denominada común y justamente crematística, responsable de la idea de que no existe límite a la riqueza y a la propiedad. Esta es producto de la experiencia y de la habilidad (y no es una forma natural).

En todo artículo hay un doble uso, ambos pertenecientes al objeto: el uso y la mercancía. Una sandalia, por ejemplo. Si se da a alguien para que la use, se está utilizando por su valor de uso. Si la cambia por algo que necesite, el cambio también es natural y es para satisfacer las necesidades ${ }^{28}$.

En la primera forma de comunidad (demos) se cambiaba lo útil por lo útil y nada más. Por ejemplo: vino por trigo. Esto es natural y sirve para la autarquía. Del simple trueque se pasó al cambio de objetos con extranjeros. Y para facilitar, se acuñó la moneda que valía por el cuño que marcaba su valor.

Instituida la moneda, del proceso necesario del cambio, sobrevino otra forma de crematística, el negocio de pequeñas ganancias. Que luego se fue tecnificando cuando los hombres descubrieron cómo y dónde se obtiene mayor provecho ${ }^{29}$.

La crematística tiene que ver con el arte de producir riqueza y dinero. Pero el dinero no es la riqueza, y a propósito de esta distinción trae Aristóteles la anécdota del rey Midas que no podía comer porque todo se le trocaba en oro, no tenía ni lo de su subsistencia.

La riqueza natural procede de la administración doméstica y tiene límite. La crematística procede del dinero, no tiene límite y su fin es la acumulación.
Termina diferenciando dos clases de crematística:

Dos formas hay, como acabamos de decir de crematística: la del negocio de pequeñas ganancias y la de la administración doméstica: necesaria ésta y honorable; aquélla -la del comercio con ganancia- justamente censurada por no ser natural sino a expensas de otros. Pero la más odiada, y con toda razón, es la usura que obtiene ganancias del dinero mismo y no del uso para el que se introdujo. Éste se hizo para ser empleado en el intercambio, mientras que el préstamo hace crecer la prole. En griego llamamos tokos [prole] a la usura, porque, como los hijos [ôéêôiìåiá, tiktomena) se parecen a los padres, así el interés engendrado por el dinero es dinero, Luego, de todas las maneras de ganar dinero ésta es la más antinatural ${ }^{30}$.

\subsection{En Santo Tomás}

En su Comentario (Libro I, Lección VI, \# 67), Santo Tomás recoge la afirmación de Aristóteles de que las diversas formas de alimentos determinan las diversas formas de vivir los hombres. Plantea que Aristóteles determina en general lo pecuniario como toda posesión y el arte que se refiere al dinero (llama lo que se refiere al dinero "lo pecuniario”), y establece la relación de este arte con la administración doméstica. Pero aquí Santo Tomás cambia el ejemplo de la lanzadera y el bronce por el ejemplo del arte de fabricar cuchillos, arte propiamente medieval relacionado con la herrería y con la fundición. Interpreta la relación entre artes y oficios.

\footnotetext{
Aristóteles, Politeia ..., Libro I, 9, 1257a (p. 149).

29 Aristóteles, Politeia ..., Libro I, 9, 1257b (p. 151).

30 Aristóteles, Politeia ..., Libro I, 10, 1258b (p. 154).
} 
No es lo mismo que un arte sea parte del otro y que sea su suministro. Pues se dice que un arte es parte de otro cuando considera algo de lo que considera el otro arte, como el arte de fabricar cuchillos es parte de la herrería, dado que el cuchillo es una clase de obra hecha de hierro.

En cambio se considera arte de suministro el que hace algo en servicio de otro arte, como el arte de la fundición del hierro suministra al arte de la herrería. Como el dinero está al servicio de la casa, parece que fuera un arte de suministro de la administración doméstica ${ }^{31}$.

En la Lección VII, \# 71-81, comenta la doctrina de Aristóteles sobre la conmutación pecuniaria, para llegar a la conclusión de que:

Es evidente, según lo dicho y hablando con verdad, que los que abundan en lo necesario para la vida son más ricos que los que abundan en dinero ${ }^{32}$.

Para terminar, dejaremos planteados algunos interrogantes:

- ¿ Tiene algún sentido para nosotros y se puede considerar vigente hoy el concepto de polis, no como un lugar, sino como comunidad política que busca el bien común, que es autárquica (autosuficiente) y autónoma?

-¿Es posible, en esta época de propaganda y de información de masas, aplicar la norma de gobernar a los hombres como seres racionales (incluso a los esclavos) dándoles el sentido de la razón?
-La norma de manejar la riqueza de acuerdo a necesidades naturales de la familia y de la polis, sin permitir que la crematística se desborde, puede plantear problemas como: ¿Es válida en economía la categoría moral de "riqueza natural”? ¿Se puede considerar todavía la "crematística" como una degeneración y lo más antinatural, cuando hasta los Estados más desarrollados y capitalistas parecen atrapados en el determinismo del sube y baja de las bolsas?

- Respecto a la ciencia de gobernar, sea la del amo, la del pater familias, la del magistrado o la del presidente, cabe la pregunta: $¿$ De verdad se ha abolido la esclavitud, al interior de la pareja, de la familia, de las instituciones, de los Estados y del orden internacional, o sólo se le ha cambiado de nombre?

- Respecto a la "guerra justa”: ¿Están vigentes los criterios defendidos en la Política por Aristóteles y comentados por Santo Tomás?

Tal vez el problema de fondo, para nosotros, no consista en tratar de ver qué está vigente de lo planteado por Aristóteles, ni tratar de explicar las argumentaciones del texto aristotélico como hizo Santo Tomás, sino plantear si de veras el hombre es un ser político como ellos creyeron (o si no, tratar de saber qué es), y si es válido considerar como natural lo que se generaliza como costumbre en una época.

\footnotetext{
Aquino y Alvernia, Comentario..., Libro I, Lección VI, \# 61 (p. 73).
}

32 Aquino y Alvernia, Comentario..., Libro I, Lección VII \# 81 (p. 83). 